DOI: $10.21066 /$ carcl.libri.2016-05(02).0008

\title{
Illustrations for Rozprávky z pradávna
}

The following pages display original illustrations by Irena Tarasová made for Rozprávky z pradávna, the 1976 Slovak edition of Croatian Tales of Long Ago by Ivana Brlić-Mažuranić (1874-1938), published in Bratislava by Mladé letá. The book comprises all eight tales found in the third Croatian edition of the collection (1926), in translation by Zlatko Klátik (1922-1990). Each story is adorned by three subtle images: a vignette on the page where the story begins, another on the page where the story ends, and a rich full-page colour illustration bled to the edges, incorporated in the text in between. Two additional vignettes accompany Klátik's afterword about the author and her tales, and the short glossary at the end, the final vignette on the very last page of the book.

Irena Tarasová is an internationally acknowledged Slovak illustrator whose pictures have appeared in books in several languages. She started her career in the 1960s, and has illustrated more than 30 children's books. Currently, Irena Tarasová is in retirement and lives in the capital of the Slovak Republic, Bratislava.

Irena Tarasová represents a lyrical line of book illustrations for children. Her work is based on the effects of a colour and the decorativeness of a collage. She is one of only a few illustrators who have focused just on illustrations for younger children. According to contemporary literary critics, Irena Tarasová has reached the very top in the aestheticisation of children's books, especially in the illustrations of the book of Ivana Brlić-Mažuranić Rozprávky z pradávna (1976). Their beauty lies in the uniform, exquisite and vibrant colour of the collages - in the use of the paper structure, on which she draws and paints with oil pastel, gouache and tempera in several layers. ${ }^{1}$

Radoslav Rusñák

\section{Ilustracije za Rozprávky z pradávna}

$\mathrm{Na}$ sljedećim se stranicama nalaze ilustracije umjetnice Irene Tarasove za slovačko izdanje Priča iz davnine Ivane Brlić-Mažuranić (1874. - 1938.), Rozprávky z pradávna (1976). Zlatko Klátik (1922. - 1990.) preveo je svih osam priča koje se nalaze u trećemu hrvatskome izdanju zbirke iz 1926. godine, a knjiga je objavljena u Bratislavi, u nakladi Mladé letá. Svaka je priča ukrašena trima ilustracijama; najprije nalazimo vinjetu na stranici gdje priča počinje, potom raskošnu ilustraciju

1 We are grateful to Irena Tarasová for giving Libri \& Liberi permission to publish the facsimiles of her original illustrations published in the Slovak translation of Croatian Tales of Long Ago (Rozprávky z pradávna, 1976) by Ivana Brlić-Mažuranić, in both printed and electronic versions of this issue of Libri \& Liberi. 
preko cijele stranice unutar priče, a na kraju i vinjetu na kraju priče. Dodatne dvije vinjete ukrašavaju Klátikov pogovor o autorici i njezinu djelu te kratak rječnik pojmova, pri čemu se vinjeta nalazi na zadnjoj stranici cijele knjige.

Irena Tarasová međunarodno je priznata slovačka ilustratorica dječjih knjiga čije su se slike pojavile u knjigama na različitim jezicima. Knjige je započela oslikavati 1960-ih godina, a njezine se ilustracije nalaze u više od 30 dječjih knjiga. Danas je u mirovini i živi u Bratislavi, glavnome gradu Republike Slovačke.

Radovi Irene Tarasove predstavljaju lirski smjer u ilustriranju knjiga za djecu, ukrasne i žanrovske naravi. Njezin se rad zasniva na učincima boje i dekorativnosti kolaža. Pripada malomu broju ilustratora koji su se usmjerili na oslikavanje djela za mlađu djecu. Prema suvremenim književnim kritičarima Tarasová je dostigla vrhunac na putu estetizacije dječje knjige, osobito u ilustracijama za Rozprávky z pradávna (1976) Ivane Brlić-Mažuranić. Njihova su odlika ujednačene, birane $\mathrm{i}$ žive boje kolaža i vješto iskorištena struktura papira na koji je umjetnica u nekoliko slojeva nanijela crteže i slike uljnim pastelom, gvašem i temperom. ${ }^{2}$

Radoslav Rusňák

2 Zahvaljujemo umjetnici Ireni Tarasovoj na suglasnosti da u tiskanome i elektroničkome izdanju ovoga broja časopisa Libri \& Liberi objavimo faksimile njezinih izvornih ilustracija objavljenih u slovačkome izdanju Priča iz davnine (Rozprávky z pradávna) Ivane Brlić-Mažuranić iz 1976. godine. 


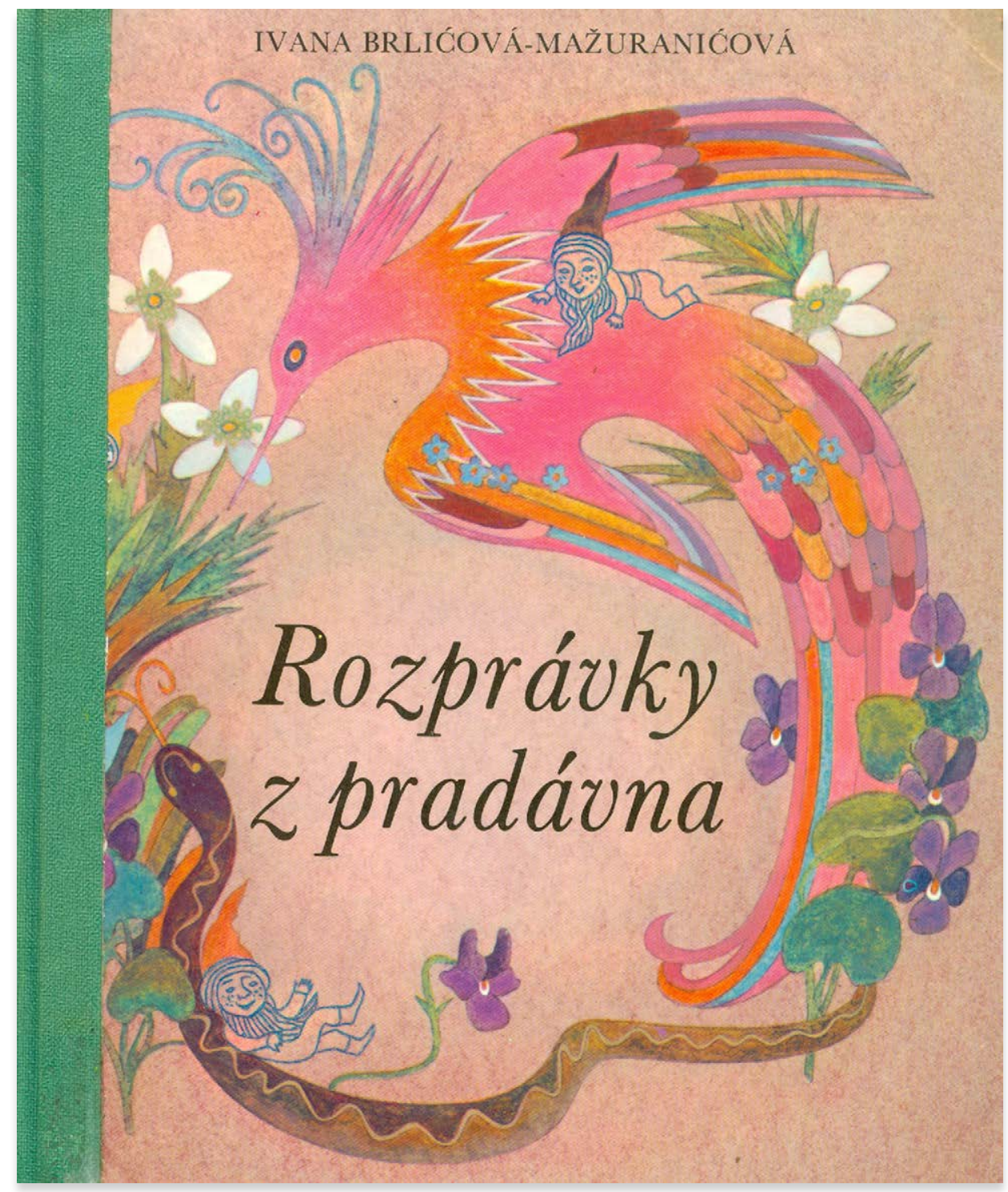

Front cover of / prednja strana korica knjige Ivana Brlićová-Mažuranićová: Rozprávky z pradávna (1976).

Cover illustration / omotna ilustracija: Irena Tarasová. 

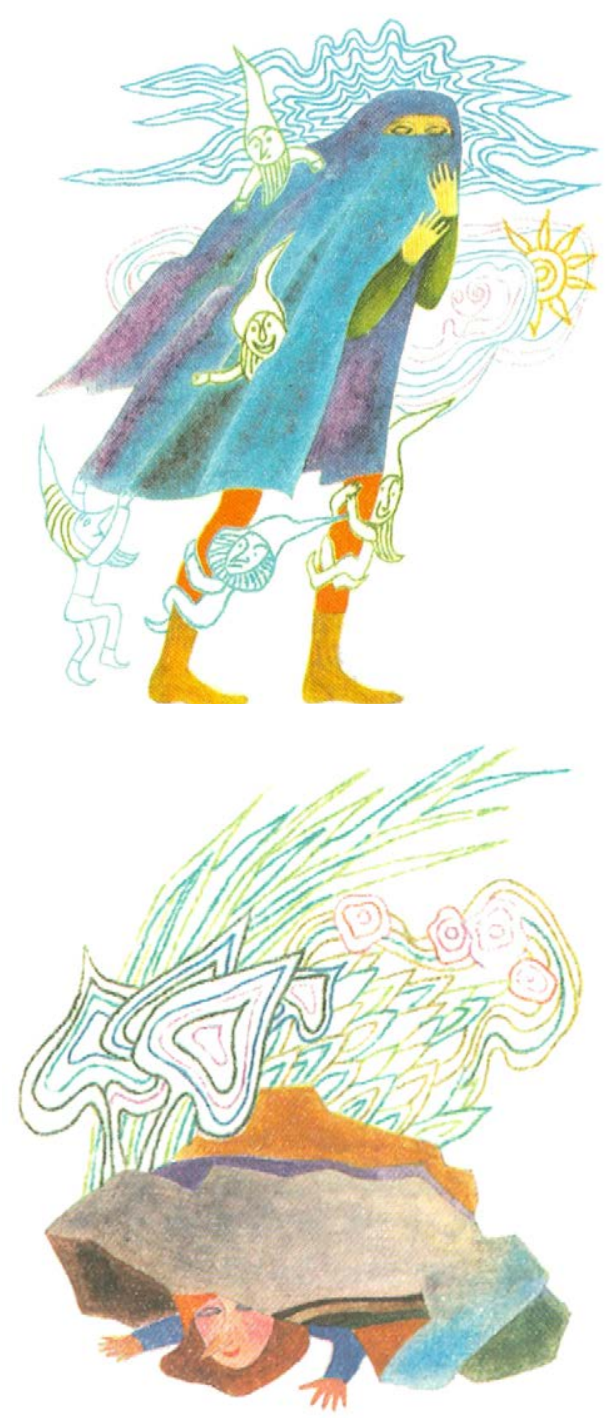

Irena Tarasová. Vignettes for the story "Ako Potech pravdu hl'adal” [How Quest Sought the Truth]. Ivana Brlićová-Mažuranićová: Rozprávky z pradávna (1976: 7, 27).

Irena Tarasová. Vinjete uz priču „Ako Potech pravdu hl'adal“ [Kako je Potjeh tražio istinu]. Ivana Brlićová-Mažuranićová: Rozprávky z pradávna $(1976: 7,27)$. 


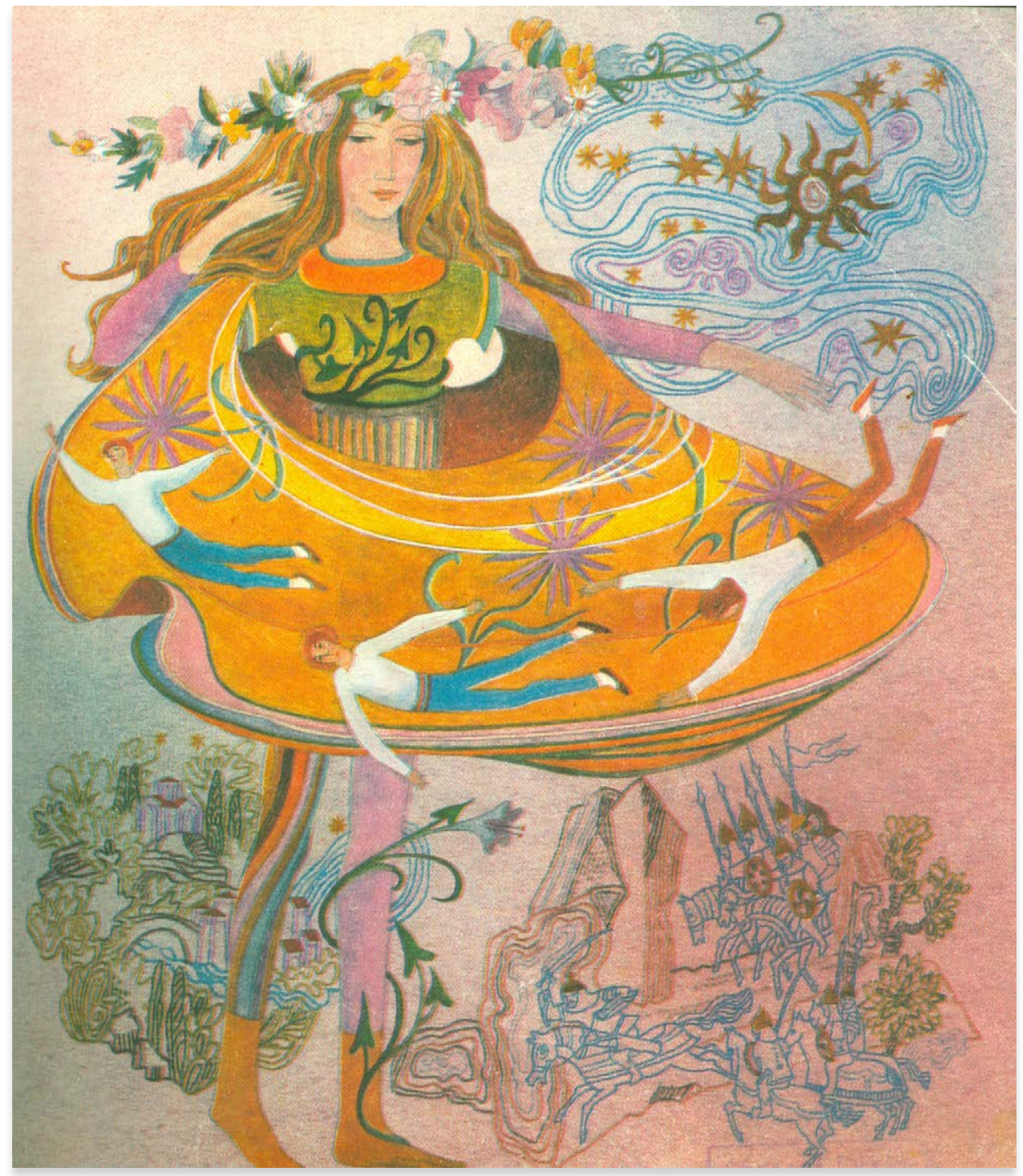

Irena Tarasová. Full page illustration for the story "Ako Potech pravdu hl'adal" [How Quest Sought the Truth]. Ivana Brlićová-Mažuranićová: Rozprávky z pradávina (1976: 17).

Irena Tarasová. Ilustracija za priču „Ako Potech pravdu hl'adal“ [Kako je Potjeh tražio istinu]. Ivana Brlićová-Mažuranićová: Rozprávky z pradávna (1976: 17). 

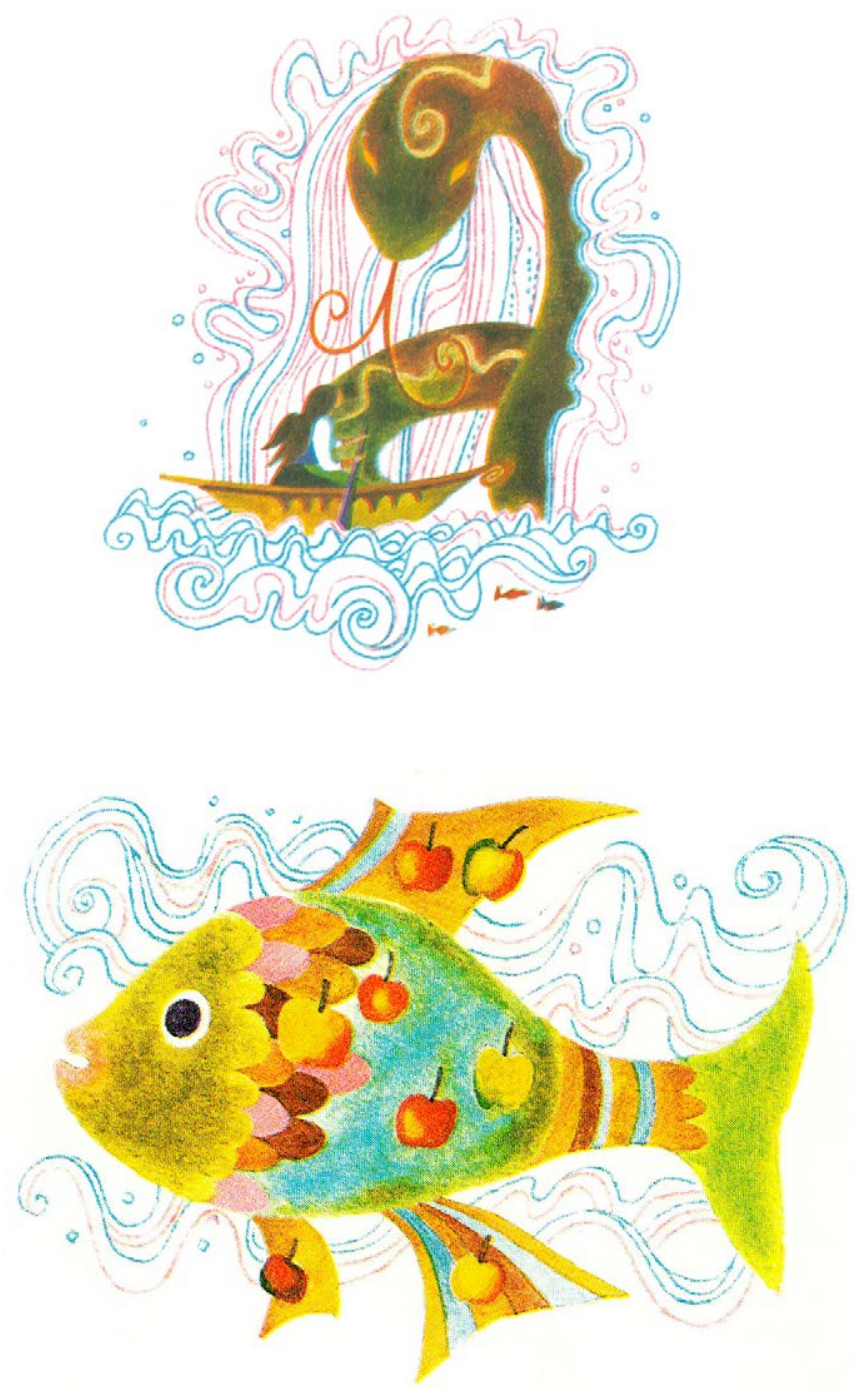

Irena Tarasová. Vignettes for the story "Rybár Palunko a jeho žena" [Fisherman

Plunk and His Wife]. Ivana Brlićová-Mažuranićová: Rozprávky z pradávna (1976: 28, 45).

Irena Tarasová. Vinjete uz priču „Rybár Palunko a jeho žena“ [Ribar Palunko i njegova žena]. Ivana Brlićová-Mažuranićová: Rozprávky z pradávna (1976: 28, 45). 


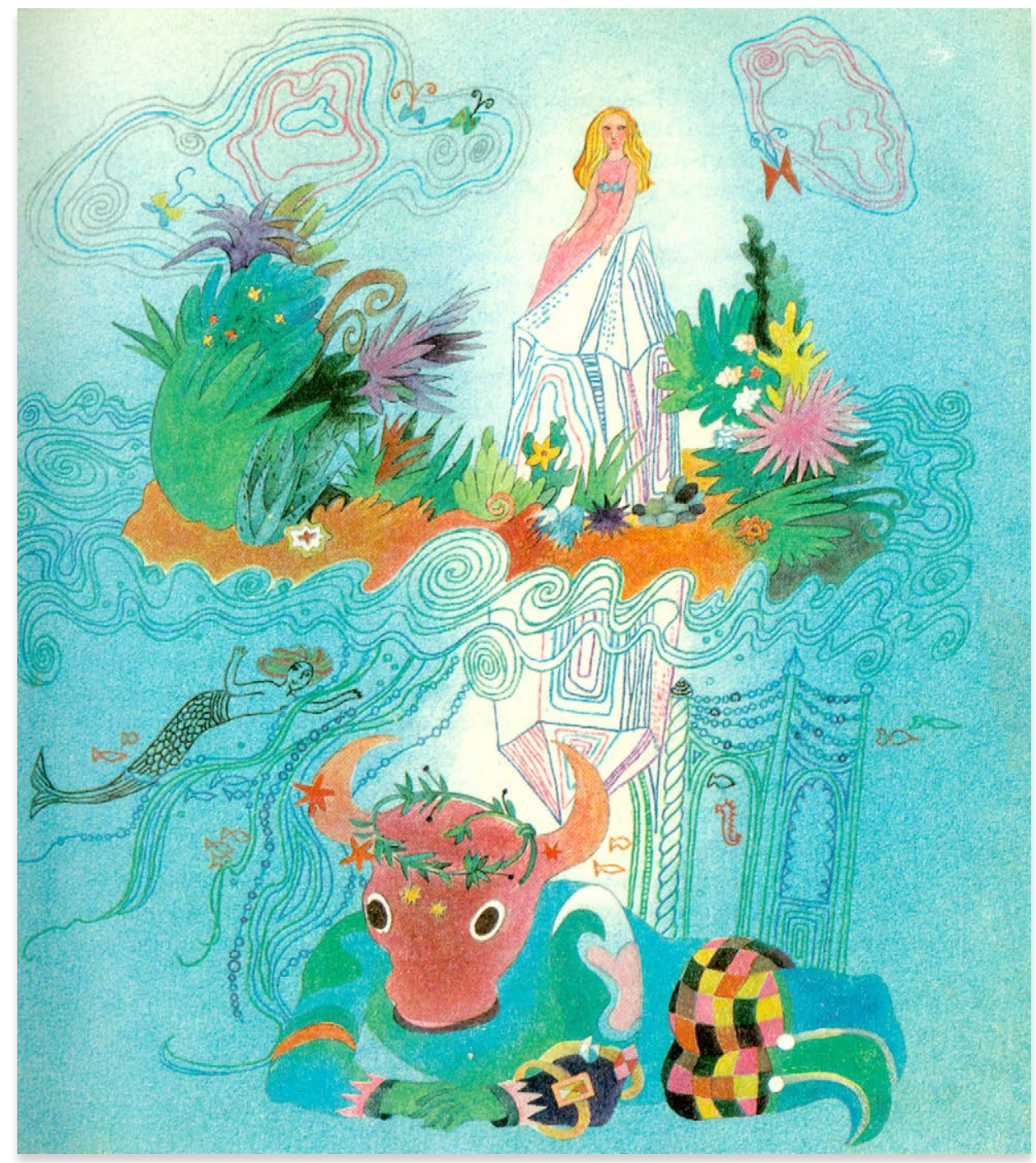

Irena Tarasová. Full page illustration for the story "Rybár Palunko a jeho žena" [Fisherman Plunk and His Wife]. Ivana Brlićová-Mažuranićová: Rozprávky z pradávna (1976: 35).

Irena Tarasová. Ilustracija za priču „Rybár Palunko a jeho žena“ [Ribar Palunko i njegova žena]. Ivana Brlićová-Mažuranićová: Rozprávky z pradávna (1976: 35). 

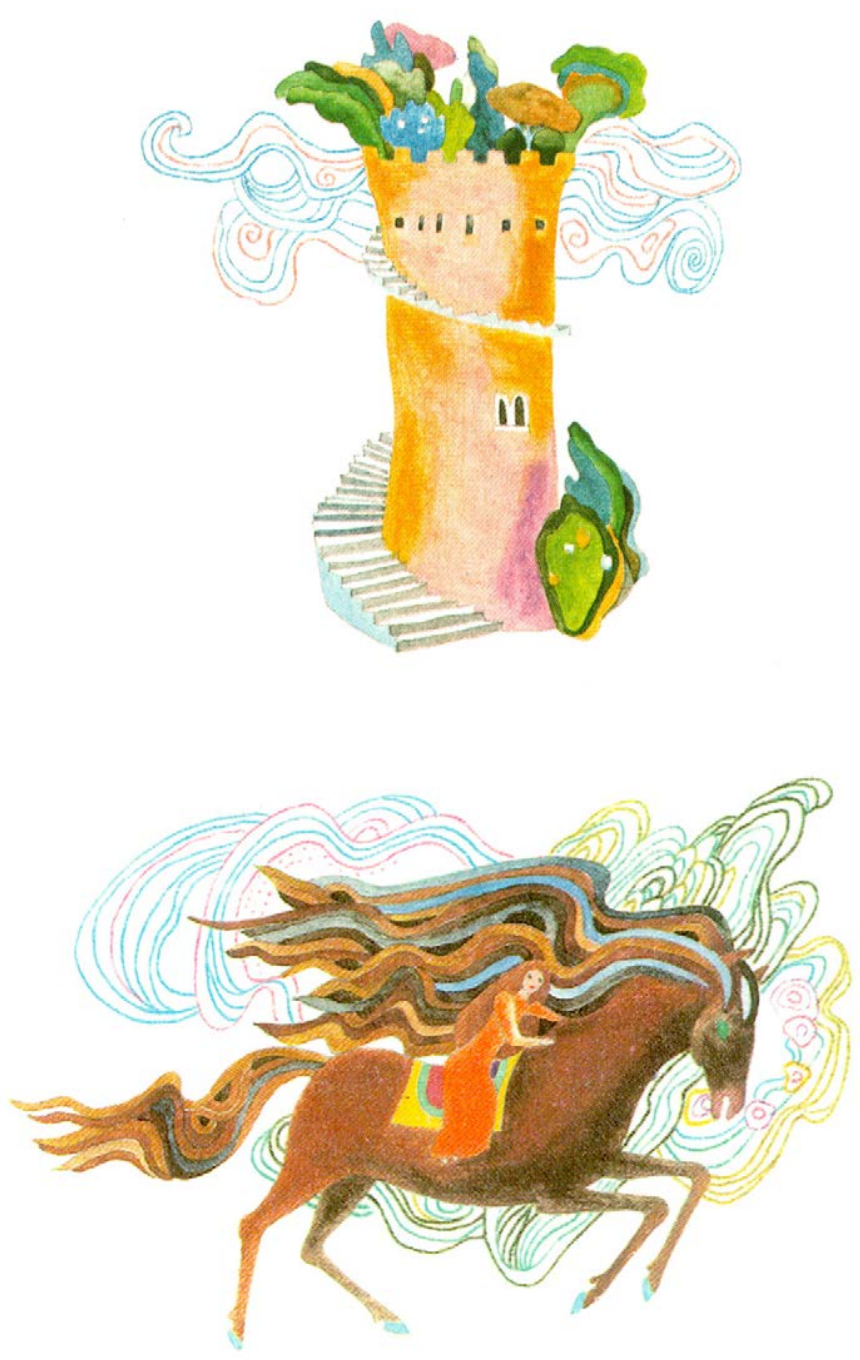

Irena Tarasová. Vignettes for the story "Rehoč" [Reygoch]. Ivana BrlićováMažuranićová: Rozprávky z pradávna (1976: 47, 65). Irena Tarasová. Vinjete uz priču „Rehoč“ [Regoč]. Ivana Brlićová-Mažuranićová: Rozprávky z pradávna $(1976: 47,65)$. 


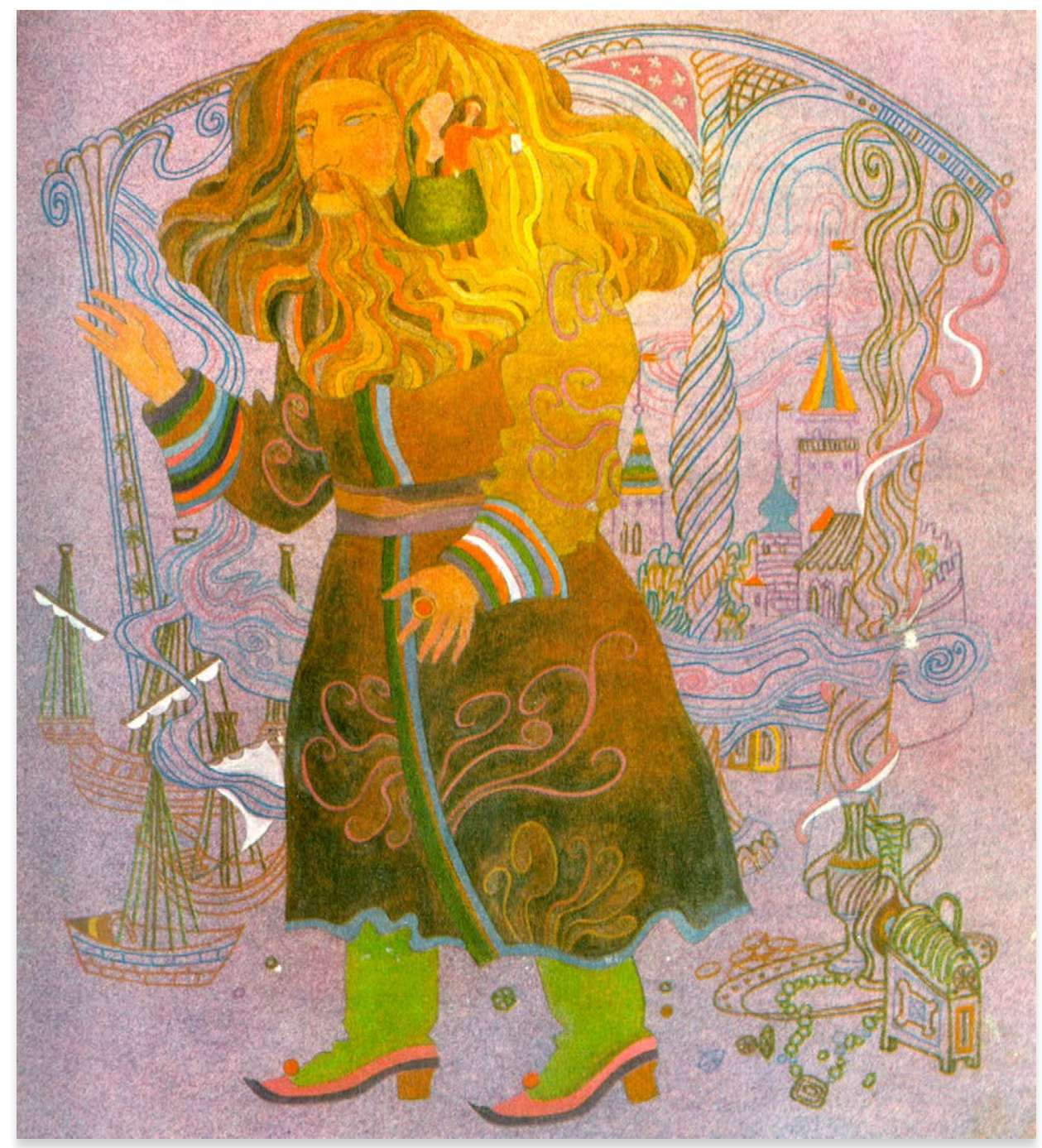

Irena Tarasová. Full page illustration for the story "Rehoč" [Reygoch]. Ivana Brlićová-Mažuranićová: Rozprávky z pradávna (1976: 55). Irena Tarasová. Ilustracija za priču „Rehoč“ [Regoč]. Ivana BrlićováMažuranićová: Rozprávky z pradávna (1976: 55). 

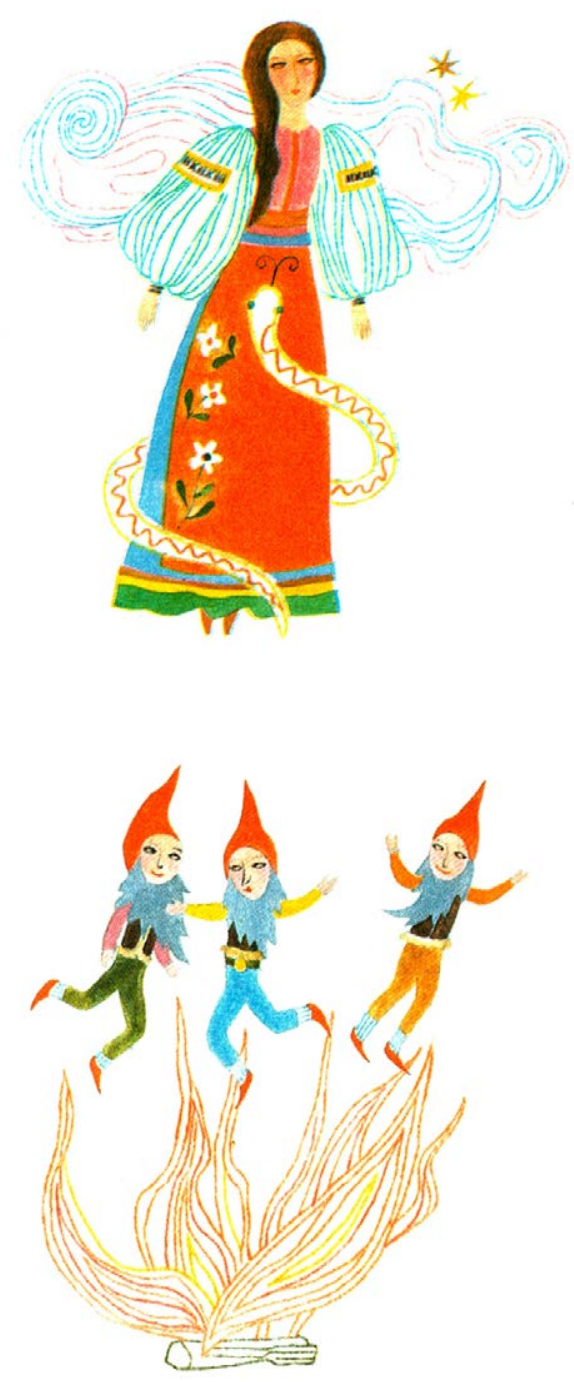

Irena Tarasová. Vignettes for the story "Striborova hora" [Stribor's Forest]. Ivana Brlićová-Mažuranićová: Rozprávky z pradávna $(1976: 67,77)$.

Irena Tarasová. Vinjete uz priču „Striborova hora“ [Šuma Striborova]. Ivana Brlićová-Mažuranićová: Rozprávky z pradávna $(1976: 67,77)$. 


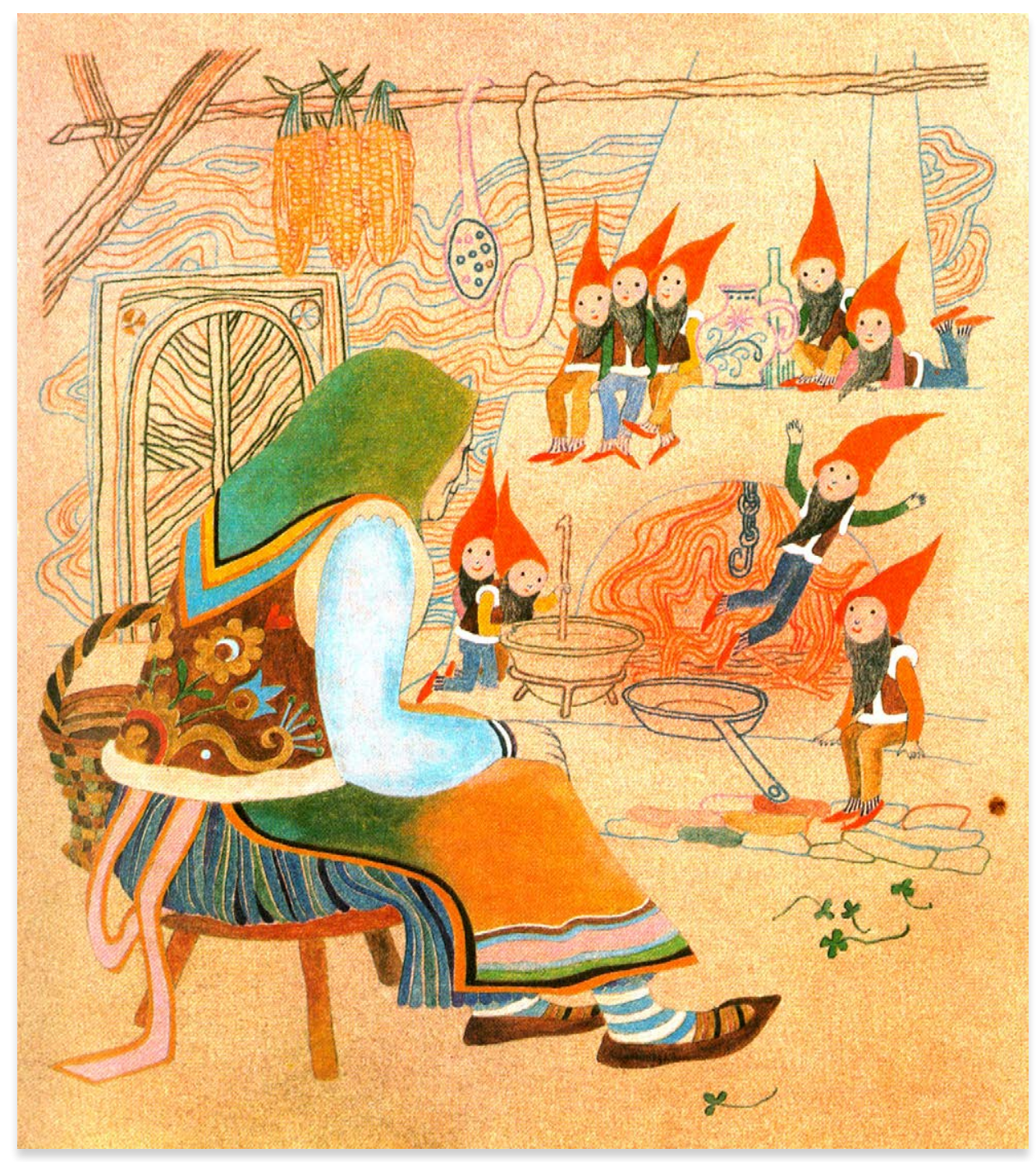

Irena Tarasová. Full page illustration for the story "Striborova hora" [Stribor's

Forest]. Ivana Brlićová-Mažuranićová: Rozprávky z pradávna (1976: 73). Irena Tarasová. Ilustracija za priču „Striborova hora“ [Šuma Striborova]. Ivana Brlićová-Mažuranićová: Rozprávky z pradávna (1976: 73). 

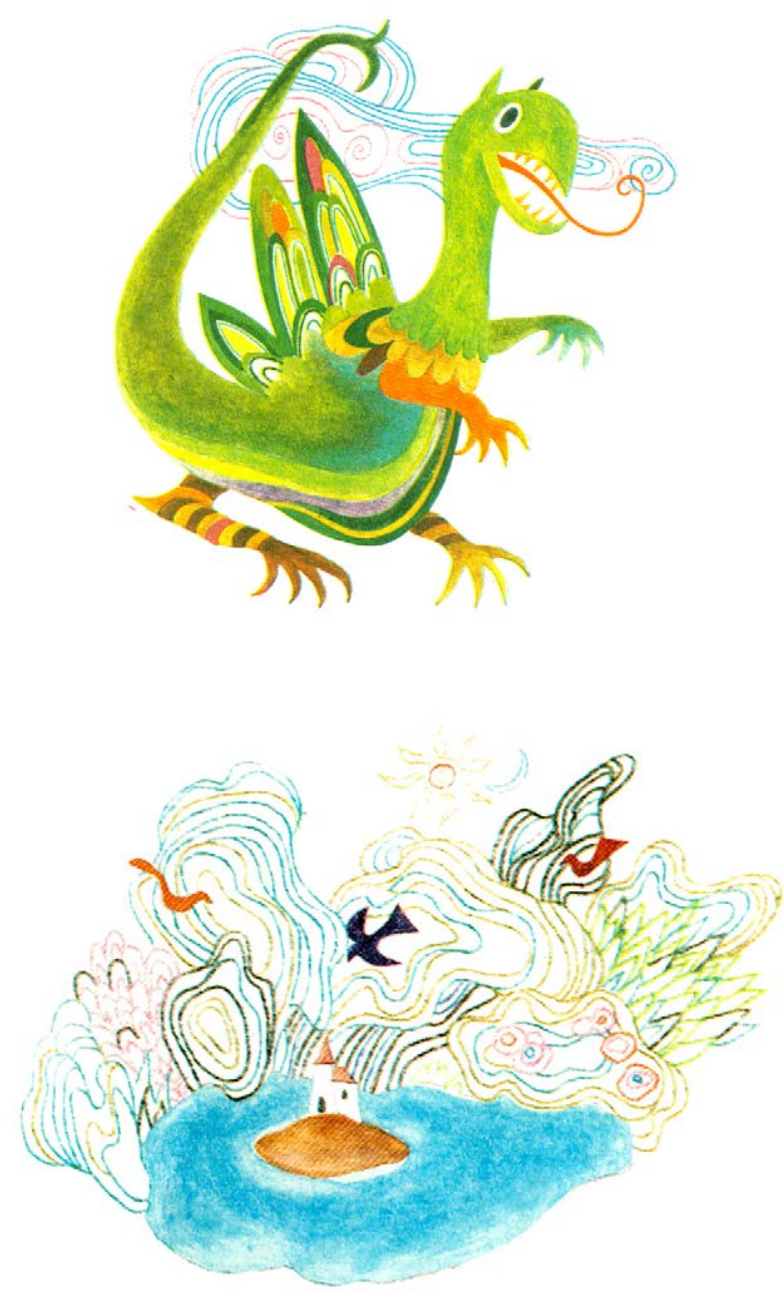

Irena Tarasová. Vignettes for the story "Braček Jelenček a sestrička Ruženka" [Little Brother Primrose and Sister Lavender]. Ivana Brlićová-Mažuranićová: Rozprávky z pradávna $(1976: 79,108)$.

Irena Tarasová. Vinjete uz priču „Braček Jelenček a sestrička Ruženka“ [Bratac Jaglenac i sestrica Rutvica]. Ivana Brlićová-Mažuranićová: Rozprávky z pradávna (1976: 79, 108). 


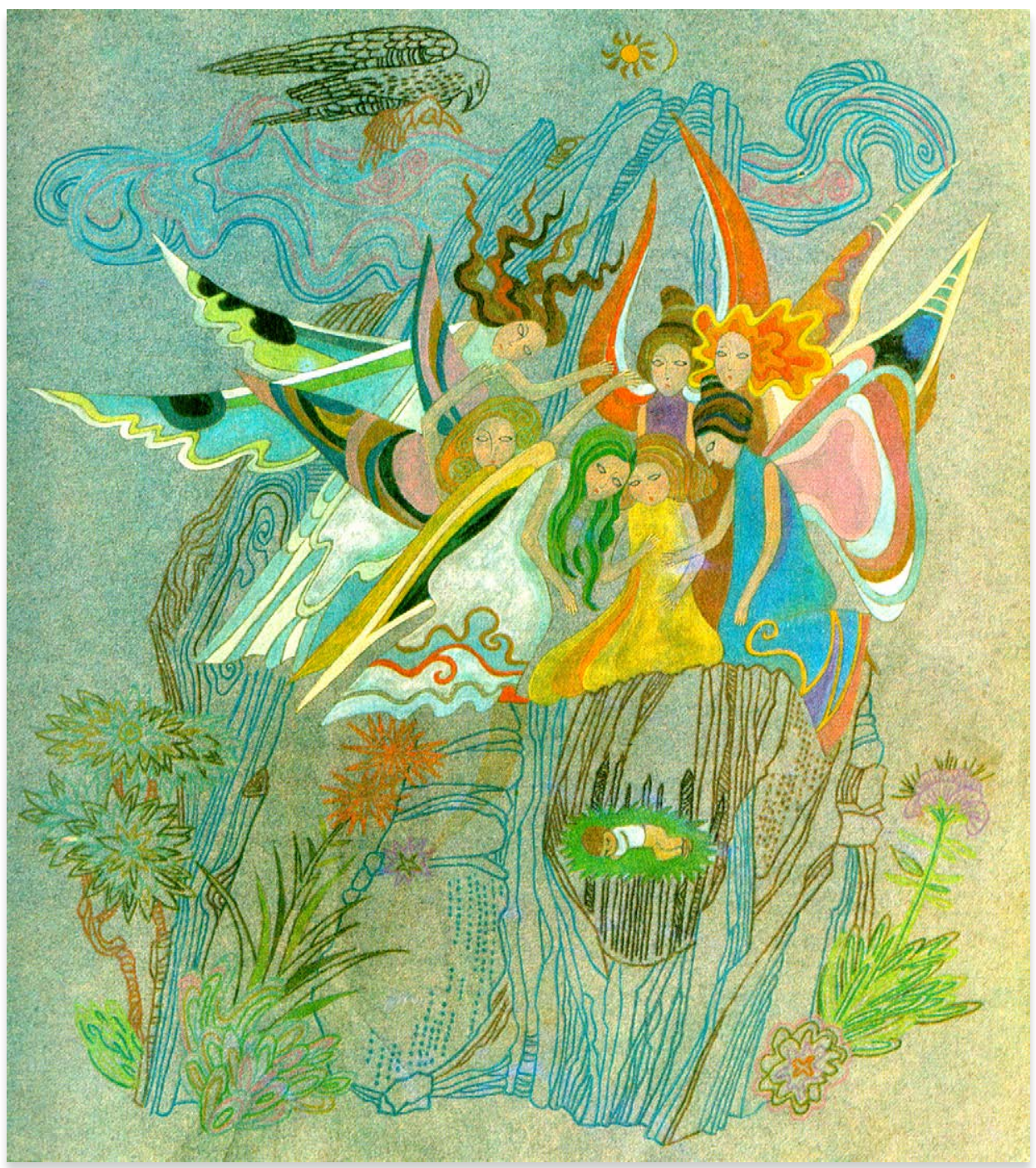

Irena Tarasová. Full page illustration for the story "Braček Jelenček a sestrička Ruženka" [Little Brother Primrose and Sister Lavender]. Ivana BrlićováMažuranićová: Rozprávky z pradávna (1976: 91).

Irena Tarasová. Ilustracija za priču „Braček Jelenček a sestrička Ruženka“ [Bratac Jaglenac i sestrica Rutvica]. Ivana Brlićová-Mažuranićová: Rozprávky z pradávna (1976: 91). 

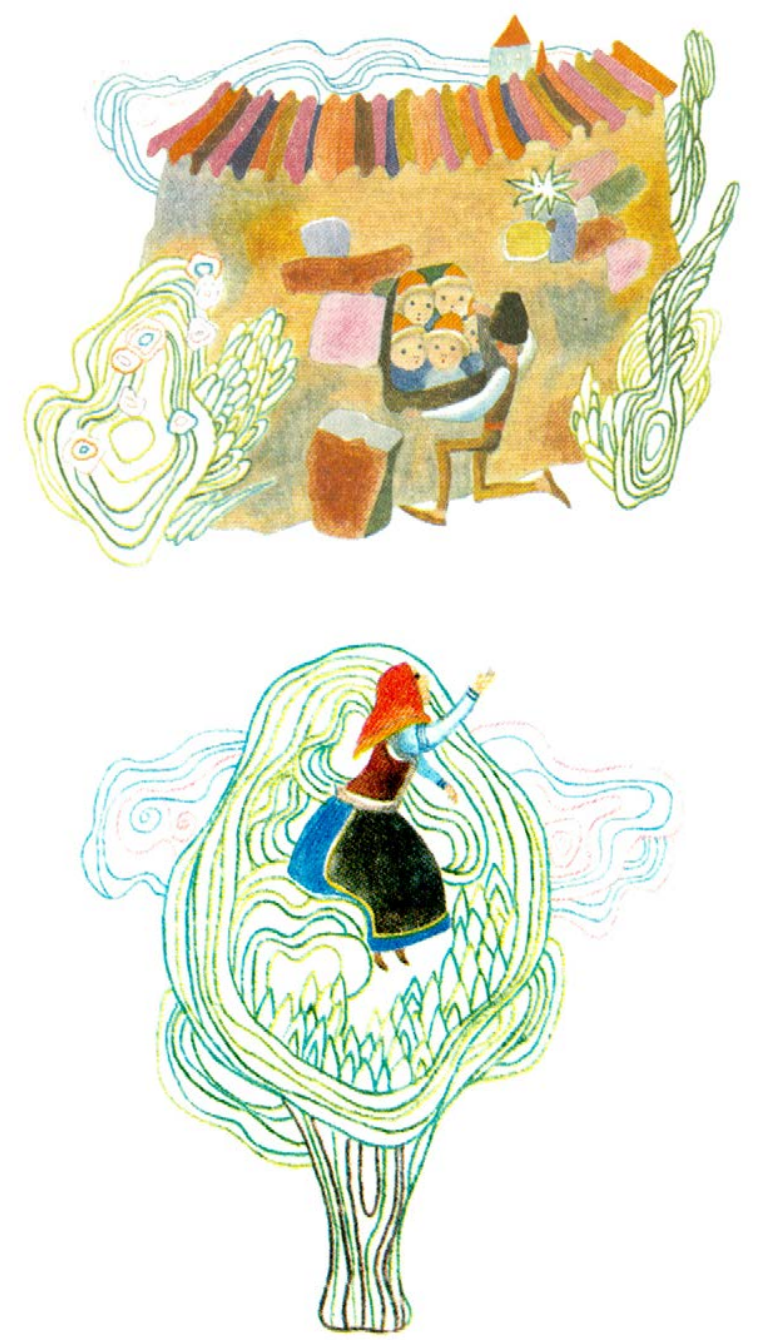

Irena Tarasová. Vignettes for the story "Tuláčik Toporček a devät' synčekovžupančekov" [Topoko the Wanderer and Nine Princes]. Ivana BrlićováMažuranićová: Rozprávky z pradávna (1976: 110, 140).

Irena Tarasová. Vinjete uz priču „Tuláčik Toporček a devät’ synčekovžupančekov“ [Lutonjica Toporko i devet župančića]. Ivana Brlićová-

Mažuranićová: Rozprávky z pradávna (1976: 110, 140). 


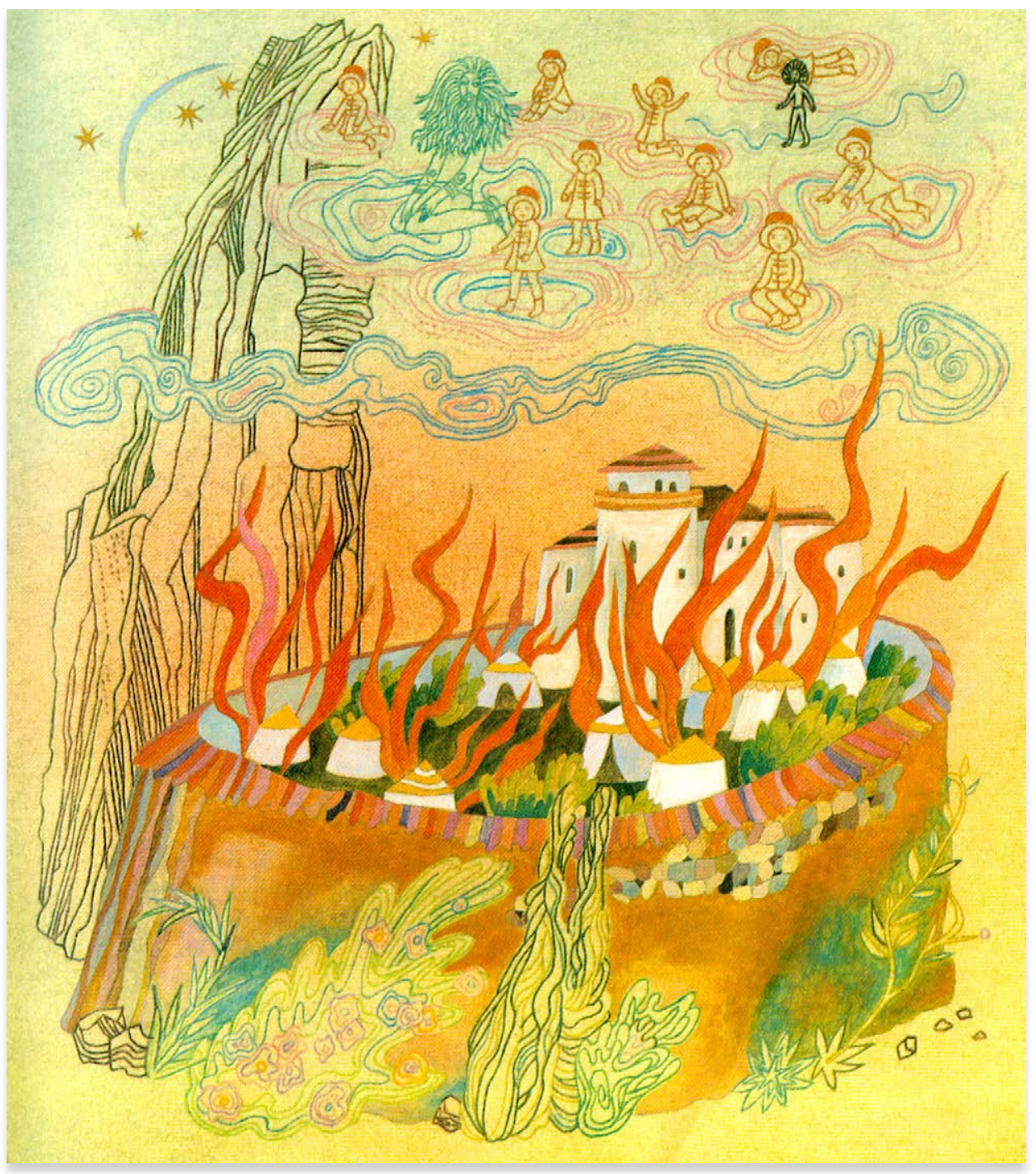

Irena Tarasová. Full page illustration for the story "Tuláčik Toporček a devät' synčekov-župančekov" [Topoko the Wanderer and Nine Princes]. Ivana BrlićováMažuranićová: Rozprávky z pradávna (1976: 123).

Irena Tarasová. Ilustracija za priču „Tuláčik Toporček a devät' synčekovžupančekov“" [Lutonjica Toporko i devet župančića]. Ivana BrlićováMažuranićová: Rozprávky z pradávna (1976: 123). 

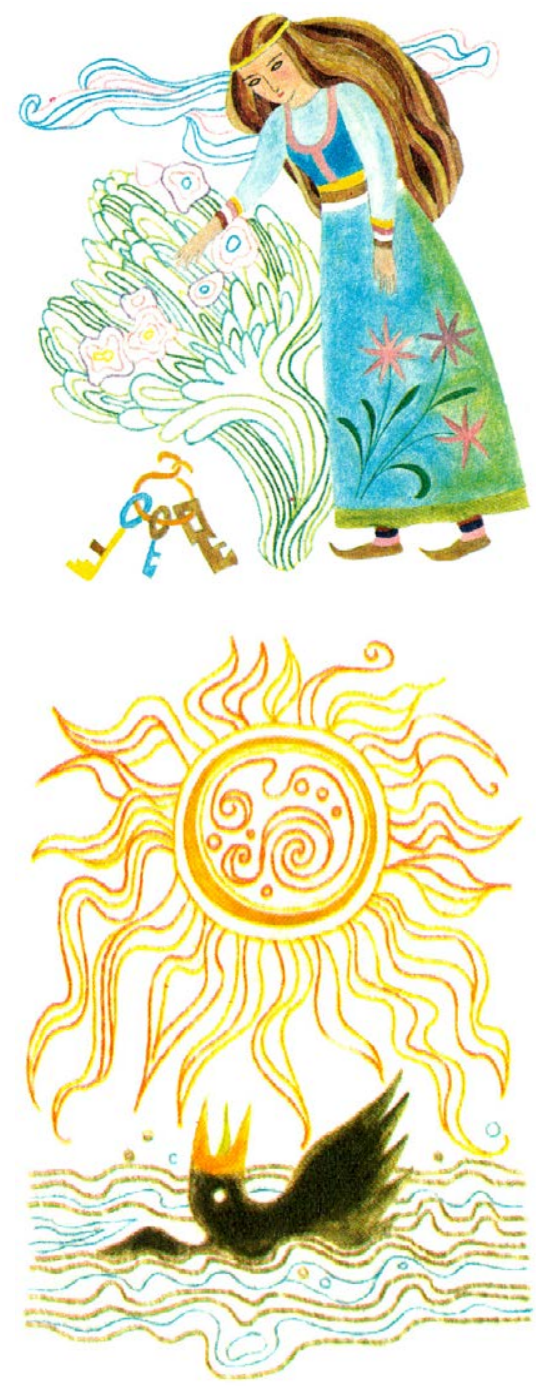

Irena Tarasová. Vignettes for the story "Slnce družba a Neva Nevestička" [Bridesman Sun and Bride Bridekins]. Ivana Brlićová-Mažuranićová: Rozprávky z pradávna (1976: 141, 152).

Irena Tarasová. Vinjete uz priču „Slnce družba a Neva Nevestička“ [Sunce djever i Neva Nevičica]. Ivana Brlićová-Mažuranićová: Rozprávky z pradávna (1976: 141, 152). 


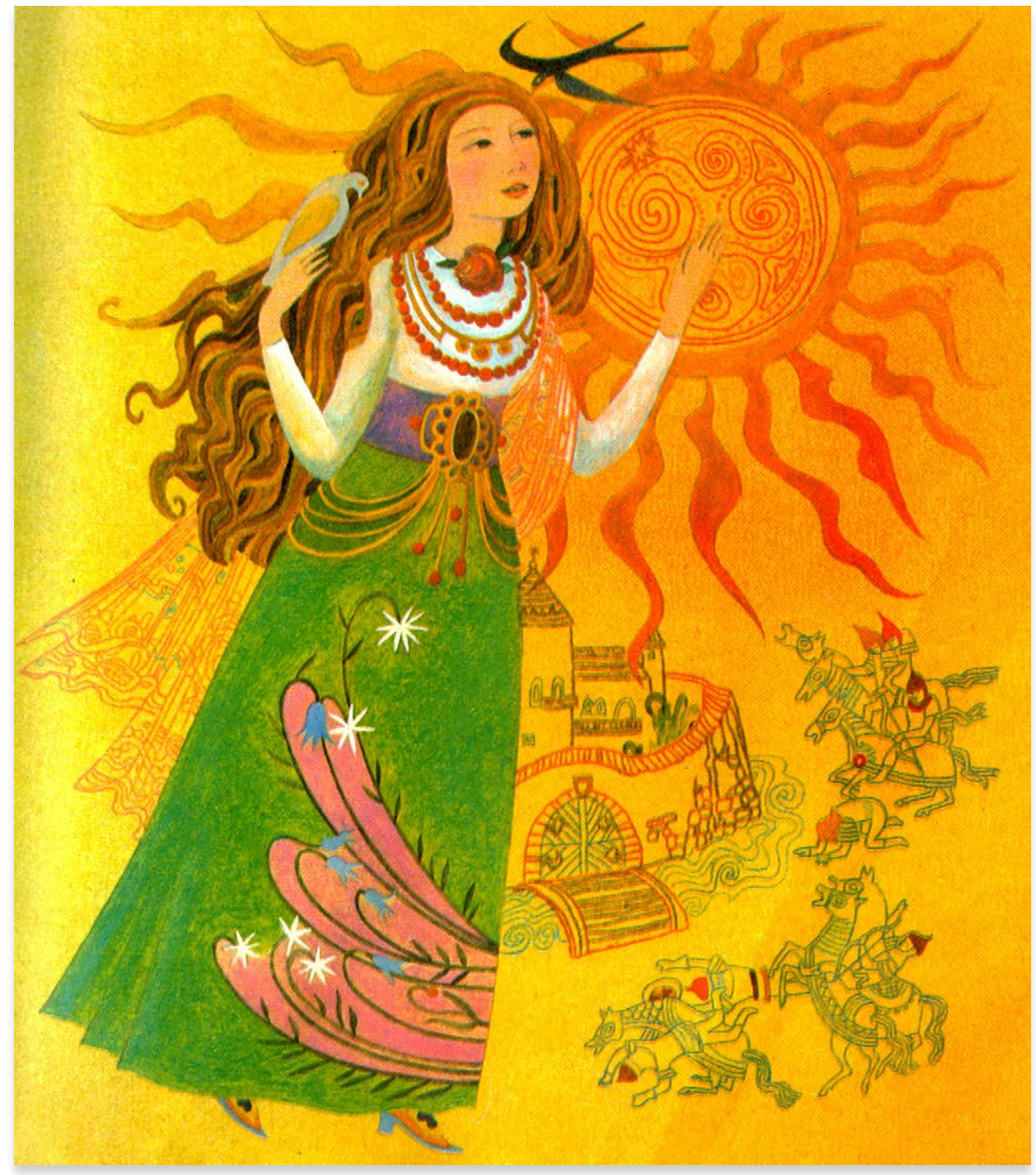

Irena Tarasová. Full page illustration for the story "Slnce družba a Neva Nevestička” [Bridesman Sun and Bride Bridekins]. Ivana Brlićová-Mažuranićová: Rozprávky z pradávna (1976: 149).

Irena Tarasová. Ilustracija za priču „Slnce družba a Neva Nevestička“ [Sunce djever i Neva Nevičica]. Ivana Brlićová-Mažuranićová: Rozprávky z pradávna (1976: 149). 

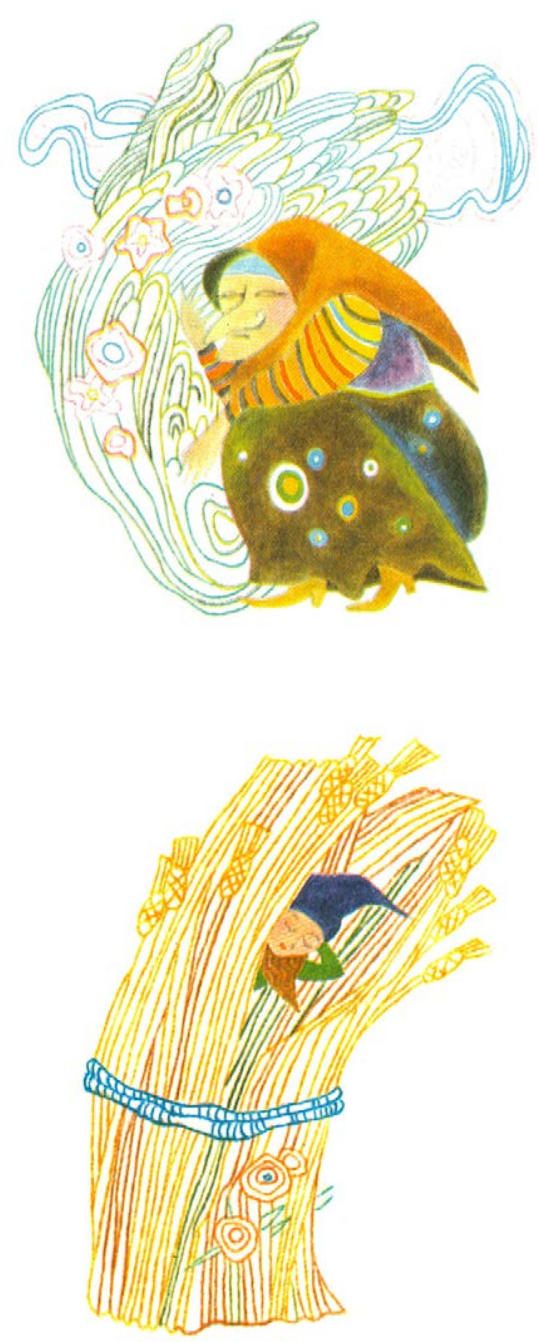

Irena Tarasová. Vignettes for the story "Jahor" [Yagor]. Ivana BrlićováMažuranićová: Rozprávky z pradávna (1976: 28, 45).

Irena Tarasová. Vinjete uz priču „Jahor“ [Jagor]. Ivana Brlićová-Mažuranićová: Rozprávky z pradávna (1976: 28, 45). 


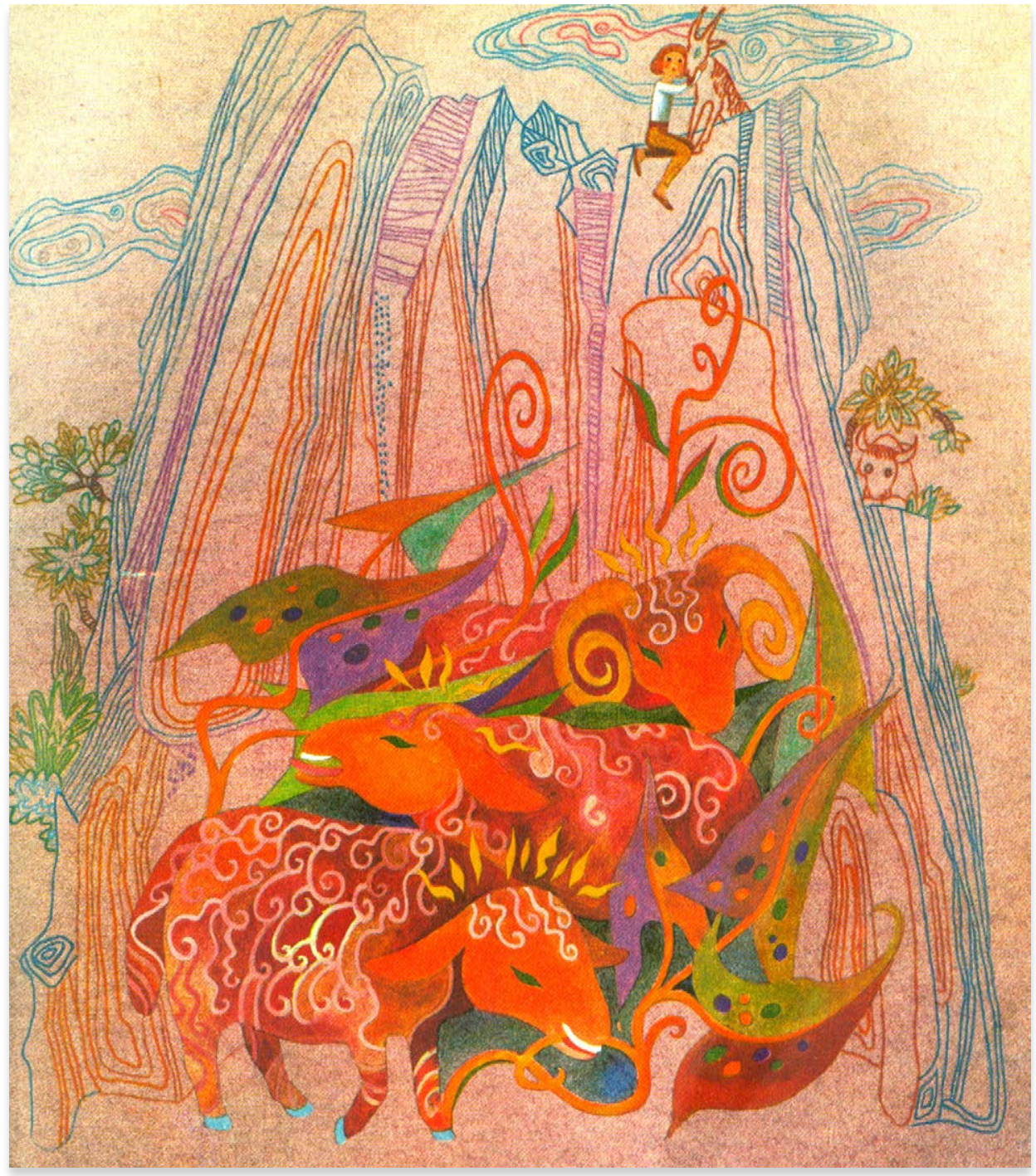

Irena Tarasová. Full page illustration for the story "Jahor" [Yagor]. Ivana Brlićová-Mažuranićová: Rozprávky z pradávna (1976: 35). Irena Tarasová. Ilustracija za priču „Jahor“ [Jagor]. Ivana Brlićová-Mažuranićová: Rozprávky z pradávna (1976: 35). 

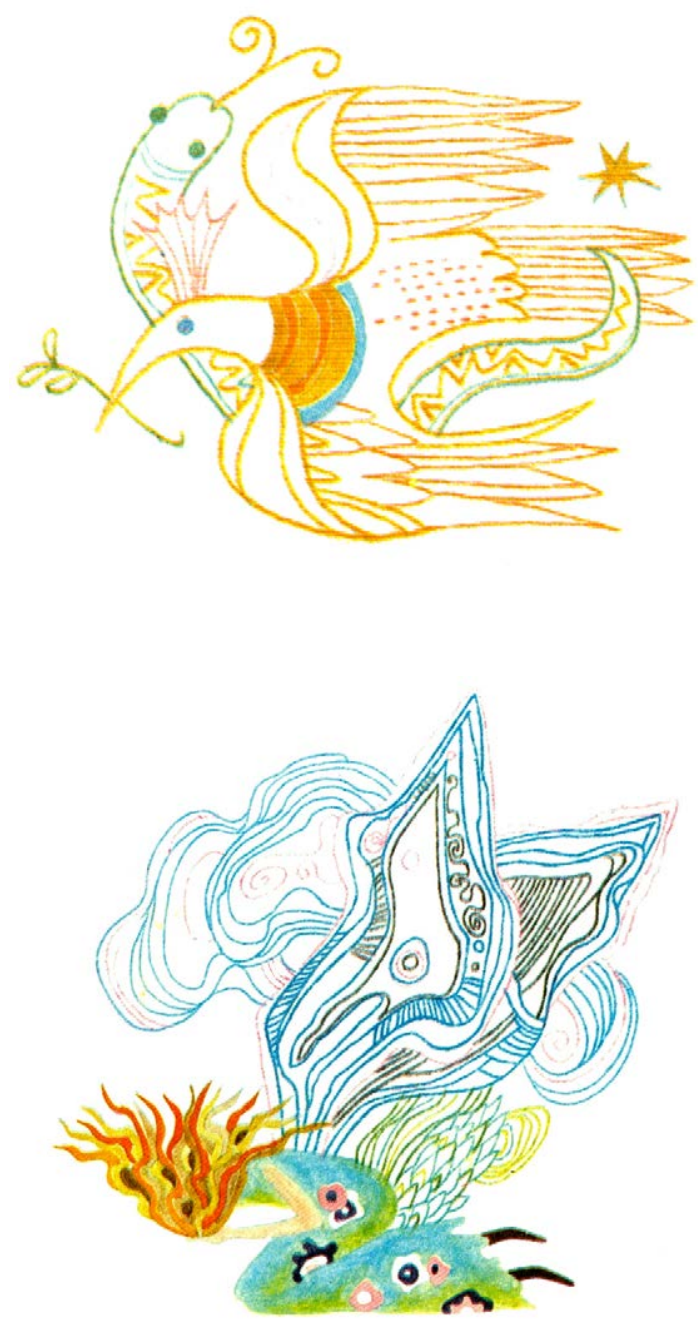

Irena Tarasová. Two vignettes in Rozprávky z pradávna [Croatian Tales of Long Ago]. Ivana Brlićová-Mažuranićová (1976: 174, 178).

Irena Tarasová. Dvije vinjete u zbirci priča Rozprávky z pradávna [Priče iz davnine]. Ivana Brlićová-Mažuranićová (1976: 174, 178). 